ảnh hưởng đến khối lượng công việc của điều dưỡng viên.

- Tổ chức những lớp bồi dưỡng kiến thức, huấn luyện về an toàn lao động theo từng vị trí chuyên môn để ĐDV có thêm kiến thức, hạn chế sai sót trong công việc.

\section{TÀI LIÊU THAM KHẢO}

1. Phùng Thanh Hùng và "Thực trạng và một số yếu tổ ảnh hưởng tới khối lươơng công việc của điều dưỡng tại một số khoa lâm sàng Bệnh viện Đa khoa Trung ương Cần Thơ năm 2016"', Tạp chí trường ĐH Y tế Công công, tâp 03, số 02-2019, mã bài báo SKPT_19_006, xuất bán 30/8/2019, trang 54-65.

2. Trân Thị Ngọc Mai (2014), "Thực trạng stress nghề nghiệp của điều dưỡng lâm sàng đang học hể cử nhân vữa làm vữa hoc tai Trường Đai học Thăng Long và Đại học Thành Tấy", Tạp chí Ý học thức hành, số 4, 110-115.

3. Đặng Thị Nguyệt (2016), "Khảo sát một số yễu tổ liên quan đển stress nghề nghiêp của điều dưỡng quận 2 thành phố Hồ Chí Minh"', Trường Đại hoc Y khoa Pham Ngoc Thach, Hồ Chí Minh.

4. Mai Hòa Nhung (2014), Tình trang stress và một số yếu tố liên quan ớ điêu dưỡng viên lâm sàng tai Bênh viên Giao thông vận tải Trung ương năm 2014, Luận văn thạc sỹ y tế công cộng, Trường đại học $Y$ tế công cộng, Hà Nội.

5. Nghiên cứu của Lê Hoàng Yến "Quuá tải và sự hăi lòng công việc của điêu dưỡng ở bệnh viện mắt trung ương", Tap chí Y học thực hành (816)-Số 4/2012.

6. Infection and mortality of healthcare workers worldwide from COVID-19: a systematic review BMJ Glob Health. 2020; 5(12)

7. Karimi A., Adel-Mehraban M. and Moeini M. (2018), "Occupational Stressors in Nurses and Nursing Adverse Events", Iranian Journal of Nursing and Midwifery Research. 23(3), 230-234.

\title{
NHÂ̂N XÉT KẾT QUẢ SỬ DỤNG TỔ CHỨC TẠI CHỖ TRONG TAQO HÌNH KHUYẾT DA ĐẦU SAU CẮT UNG THƯ
}

\section{TÓM TẮT}

Mục tiêu: Mô tả đặc điểm lâm sàng - phân loại khuyết da đâu sau cắt ững thư và đánh giá kết quả sử dụng tổ chức tại chỗ tạo hình che phủ khuyết da đâu sau cắt ung thư. Đối tượng và phương pháp: 25 bệnh nhân khuyết da đâuu sau cắt ung thư đưỡc điều trị bằng phẫu thuât tao hình với tổ chức tại chỗ; nghiên cứu hồi cứu can thiệp lâm sàng không nhóm chứng. Kết quả: Tuổi trung bình của bệnh nhân là 66,33; nguyên nhân chủ yếu là $K$ biểu mồ tế bào vảy và tế bào đáy; phẫu thuật cắt rộng tổn thương tạo nên khuyết da lớn $>20 \mathrm{~cm}^{2}$ và tạo hình bằng vạt có cuống mạch kết hợp ghép da nơi lây vạt chiếm $52 \%$. Kết quả gần loại tốt 68\%; kết quả xa loại tốt đạt 80\%. Kết luận: Vùng da đâu có tổn thương hay gặp là vùng đỉnh, đỉnh -chẩm và thái dương, tỷ lệ tổn khuyết vừa và lớn chiếm $72 \%$, có $28 \%$ thâm nhiễm sâu (cốt mạc, xương, màng não). Chỉ định đóng trực tiếp với các tổn khuyết nhỏ $\left(<5 \mathrm{~cm}^{2}\right)$ và sử dụng vạt da cân ngẫu nhiên với các tổn khuyết trung bình $\left(5-20 \mathrm{~cm}^{2}\right)$ là hoàn toàn phù hợp, trong khi kết hợp vạt cuống động mạch thái dương nông hoặc động mạch chẩm kểt hợp ghép da xẻ đối che phủ phần cho vạt để che phủ các tổn khuyết lớn $\left(>20 \mathrm{~cm}^{2}\right)$ là phương án hữu dung, an toàn, hiệu quả cao đặc biệt đối với nhóm bệnh nhân lớn tuổi có nhiều yếu tố bệnh lý nền, thể trạng sức khoẻ không đảm bảo cho các phương pháp

*Bệnh viện TWQĐ 108.

Chịu trách nhiệm chính: Lê Diệp Linh

Email: ledieplinh@yahoo.com

Ngày nhận bài: 13/5/2021

Ngày phản biên khoa học: 8/6/2021

Ngày duyệt bài: 10/7/2021
Lê Diệp Linh*, Vũ Ngọc Lâm*, Nguyễn Trọng Nghĩa*, Nguyễn Thu Phương*

khác như giãn da, vi phẫu.

Tư khoá: Ung thư da đầu, khuyết hổng da đầu, vạt cuống mạch thái dương nông, vạt cuống mạch chẩm

\section{SUMMARY \\ EVALUATION OF LOCAL TISSUE USED IN SCALP DEFECT RECONSTRUCTION FOLLOWING CANCER TUMOR RESECTION}

Objectives: This study will describe the clinical features and introduce a classification of the scalp defect after cancer resection; evaluation of the surgical effectiveness of scalp defect treatment by local tissue. Subjects and methods: 25 patients with scalp defects following cancer tumor resection are treated by reconstructive surgery with local flaps; Non-controlled clinical intervention, prospective study. Results: The main cause is squamous and basal cell epithelial cancer; type scalp defects more than $20 \mathrm{~cm}^{2}$ following cancer tumor resection has been covered by using local flap combined with skin grafting accounts for $52 \%$. The good short-term results were $68 \%$; the good far results were $80 \%$. Conclusion:The most common scalp lesions are the apex, apex - occipital and temporal regions, with moderate and large defects accounting for $72 \%$, with $28 \%$ of deep infiltrates (sclera, bone, meninges). Direct closure with small defects $(<5 \mathrm{~cm} 2)$ and the use of random skin flaps with medium defects $\left(5-20 \mathrm{~cm}^{2}\right)$ are completely appropriate. Superficial temporal artery or occipital artery pedicle combined with split skin graft to cover the flap for large defects $\left(>20 \mathrm{~cm}^{2}\right)$ is a useful and safe option, giving the best results especially for the group of elderly patients has many underlying pathological factors, their health status is not guaranteed for other methods such as skin 
expanding, microsurgery.

Key words: Scalp defect, scalp cancer, superficial temporal pedicle flap, occipital pedicle flap.

\section{I. ĐĂT VẤN ĐỀ}

Da đâu có cấu trúc giải phẫu riêng biêt với chức năng đắc biêt là che phủ hộp so, chính vì vậy khi đã có tổn khuyết lớn da đầu thì bắt buộc phải có giải pháp tạo hình che phủ. Tỉ lệ khuyết da đầu sau cắt bỏ ung thư $(K)$ da đầu trên bênh nhân lớn tuổi, có nhiều bệnh lý kèm theo có xu hướng tăng cao với kích thước lớn, tổn thương phức tạp kết hợp bênh lý nền nhiều đặt ra yêu câu lựa chọn phương pháp tạo hình hiệu quả và an toàn với thời gian phẫu thuật ngắn.

Đã có nhiều phương pháp cũng như chất liệu tạo hình che phủ tổn khuyết lớn da đầu với những ưu nhược điểm riêng. Giãn da là một phương pháp có nhiều ưu điểm tuy nhiên cần nhiều lần phâuu thuật, chi phí tốn kém. Vạt da tự do với kĩ thuât vi phẫu là phương pháp rất hiêu quả với khối lượng chất liệu lớn, tuy nhiên tiến hành phức tạp, nguy cơ tắc mạch cao với những bệnh nhân già, bệnh lý đái tháo đường, cao huyết áp, xơ vữa mạch...

Vat da đầu tai chỗ với ưu điểm vượt trọi về chất lượng da, kỹ thuật đơn giản, an toàn, dễ thực hiện, thời gian phẫu thuật và phục hồi nhanh là giải pháp rất hiệu quả cho những trường hợp bệnh nhân trên. Trong thời gian gần đây chúng tôi đã điều trị cho nhiêu trường hợp khuyết da đầu sau cắt ung thư có kết quả tốt, tuy nhiên cần một đánh giá khoa học về chỉ định, kỹ thuật, tai biến biến chứng... của phương pháp này, vì vậy chúng tôi thực hiện đề tài: "Nhận xét kết quả sử dụng tổ chức tại chỗ trong tạo hình khuyết da đầu sau cắt ung thư" với hai mục tiêu:

- Mô tả đặc điểm lâm sàng và phân loại tổn thương khuyết da đầu do ung thur.

- Dánh giá kết quả sử dung tố chức tại chố tạo hinh che phủ khuyêt da đầu sau cắt ung thư

\section{II. ĐỐI TƯỢNG VÀ PHƯƠNG PHÁP NGHIÊN CỨU}

2.1. Đối tượng nghiên cứu. Các bệnh nhân có tổn khuyết da đầu bởi nguyên nhân sau cắt rộng $\mathrm{K}$ vùng da đầu và được điều trị phẫu thuật tạo hình che phủ tổn khuyết bằng các phương pháp: đóng vết mổ trực tiếp, vạt ngẫu nhiên tại chỗ và sử dụng vạt có cuống mạch như vạt da cân cơ thái dương nông hoặc vạt chẩm, điều trị tại Khoa phẫu thuật hàm mặt và tạo hình - Bênh viện TƯQĐ108 trong khoảng thời gian từ tháng 01/2015 đến tháng 08/2020.

\subsection{Phương pháp nghiên cứu}

2.2.1. Thiết kế nghiên cứu. Sử dụng phương pháp nghiên cứu hồi cứu mô tả lâm sàng cắt ngang không có nhóm chứng, số liệu sử dung làm mẫu nghiên cứu lấy từ bệnh án lưu trữ tại phòng lưu trữ hồ sơ bệnh án của Bệnh viện TƯQĐ 108.

Mẫu nghiên cứu thuận tiện là các bệnh nhân khám và điều trị tai Khoa phấu thuât hàm mặt và tạo hình- Bênh viện TƯQĐ 108 trong khoảng thời gian từ tháng 01/2015 đến 08/2020 thỏa mãn tiêu chuẩn lựa chon và tiêu chuẩn loai trừ sau:

- Tiêu chuân lứa chọn: các bệnh nhân có tổn khuyết da đầu do ung thư được phẫu thuật tại Khoa phẫu thuật hàm mặt và tạo hình- Bệnh viện TƯQĐ 108 và có theo dõi đánh giá kết quả ít nhất sau 06 tháng phẫu thuât .

- Tiêu chuẩn loại trừ: các bệnh nhân có tổn khuyết da đâu không do ung thư và bệnh nhân có tổn khuyết da đầu do ung thư sử dụng các phương pháp tạo hình che phủ khác, hoặc không theo dõi không được đánh giá kết quả sau phẫu thuât.

2.2.3. Kỹ thuật tiến hành: Bênh nhẩn được thăm khám, phân loại, đánh giá tổn thương, lển kế hoạch điều trị, lựa chọn phương pháp phẫu thuật phù hợp để che phủ kín tổn khuyết da đầu sau cắt bỏ vùng bênh lý.

- Phân loai tổn thương. Trong nghiên cứu, diện tích tổn khuyết được đo trên hình vẽ kiểu đổi chiếu tỷ lệ $1: 1$ lên tấm nylon kẻ ô vuông bàn cờ với kích thước $1 \mathrm{~cm}^{2}$ mỗi ô (tracing overlays method) và sử dụng phương pháp chia mức độ tổn khuyết của tác giảCherubino M.(2013)[5], chia diên tổn khuyết da đầu thành ba nhóm:

- Tổn khuyết nhỏ: diện tích $<5 \mathrm{~cm}^{2}$.

- Tổn khuyết trung bình: diện tích từ $5 \mathrm{~cm}^{2}$ đến $20 \mathrm{~cm}^{2}$.

- Tổn khuyết lớn: diên tích $>20 \mathrm{~cm}^{2}$.

- Các phương pháp che phủ khuyết da đâu được sử dụng

(1) Đóng trực tiếp vết mổ.

(2) Sử dụng vạt ngẫu nhiên: vạt xoay, vạt đẩy, vạt chuyển

(3) Vạt có cuống mạch: cuống động mạch thái dương nông hoặc cuống động mạch chẩm.

Khi sử dụng vạt tại vị trí lấy vạt nếu cần ghép da thì chúng tôi sử dụng da xẻ đôi lấy từ vùng da đầu lành lân cận.

\subsection{4. Đánh giá kết quả:}

- Đánh giá kết quả gần: Khi bênh nhân ra viện. Dựa trên hai tiêu chí: sức sống của vạt cũng như diện tích che phủ.

+ Tốt: vạt có màu hồng, bờ không viêm, không chảy dịch, không có dấu hiệu nhiễm khuẩn; diện tích che phủ: từ 70\% -100\% tổn khuyêtt. 
+ Khá: Vạt có nốt phỏng hay hoại tử nhỏ, bờ viêm, bục vểt mổ một phần; diện tích che phủ: từ $50 \%-70 \%$ tổn khuyết.

+ Kém: Vạt có nguy cơ hoại tử cao, chảy dịch vàng, vết thương nhiễm khuẩn; diện tích che phủ: dưới $50 \%$ tổn khuyết.

- Đánh giá kết quả xa: Được thực hiện sau khi bệnh nhân ra viện ít nhất 6 tháng. Bệnh nhân trả lời câu hỏi theo mẫu có sẵn. Dựa trên hai tiêu chí: tình trạng da đầu vùng tổn khuyết và tình trạng mọc tóc của vùng da đầu mang tóc.

+ Tốt: độ đàn hồi, màu sắc da tương tự vùng da đầu xung quanh, sẹo nhỏ, không lồi, không tạo ra ranh giới với vùng da liền kề; tình trạng mọc tóc của vùng da đầu mang tóc: tương tự vùng da xung quanh.

+ Khá: độ đàn hồi, màu sắc da không giống da đầu xung quanh, sẹo gây biến dạng nhẹ vùng lân cận; tình trạng mọc tóc của vùng da đâu mang tóc: tóc mọc thưa hơn vùng da xung quanh.

+ Kém: độ đàn hồi, màu sắc không giống da xung quanh, tăng cảm giác đau, sẹo gây co kéo, biến dạng tổ chức; tình trạng mọc tóc của vùng da đầu mang tóc: không mọc tóc.

\section{KẾT QUẢ NGHIÊN CỨU}

3.1. Tuổi - giới: 25 bệnh nhân đủ điều kiện theo yêu cầu của đối tượng nghiên cứu được chọn với độ tuổi trung bình là $63,33(+/-17,85$; trẻ tuổi nhẩt là 31 tuối, lớn tuổi nhất là 72) với tỳ lệ nam 15/25 (60\%), nữ 10/25 (40\%).

3.2. Nguyên nhân - thời gian từ khi mắc bệnh đến khi được phẫu thuật

Bảng 1. Nguyển nhân - thời gian mắc bênh

\begin{tabular}{|c|c|c|c|c|}
\hline & $\begin{array}{c}\mathbf{< 1} \\
\text { năm }\end{array}$ & $\begin{array}{c}\mathbf{1 - 5} \\
\text { năm }\end{array}$ & $\begin{array}{c}\mathbf{>} \text { 5 } \\
\text { năm }\end{array}$ & Tổng \\
\hline $\begin{array}{c}\text { K tế bào } \\
\text { vảy }\end{array}$ & 8 & 3 & & $\begin{array}{c}11 / 25 \\
(44 \%)\end{array}$ \\
\hline $\begin{array}{c}\text { K tế bào } \\
\text { đáy }\end{array}$ & 5 & 5 & & $\begin{array}{c}10 / 25 \\
(40 \%)\end{array}$ \\
\hline Sarcom & 2 & & $\begin{array}{c}02 / 25 \\
(08 \%)\end{array}$ \\
\hline $\begin{array}{c}\text { K màng } \\
\text { não }\end{array}$ & & 1 & & $\begin{array}{c}01 / 25 \\
(04 \%)\end{array}$ \\
\hline $\begin{array}{c}\text { K tuyến } \\
\text { bã }\end{array}$ & 1 & & & $\begin{array}{c}01 / 25 \\
(04 \%)\end{array}$ \\
\hline Tổng & $\begin{array}{c}16 / 25 \\
(64 \%)\end{array}$ & $\begin{array}{c}09 / 25 \\
(36 \%)\end{array}$ & 0 & \\
\hline
\end{tabular}

Nhận xét: Nguyên nhân chủ yếu gây tổn khuyết da đầu là $K$ tế bào vảy và $K$ tế bào đáy với khoảng thời gian bệnh tiến triển dưới 1 năm là $16 / 25(64 \%)$.

\subsection{Triệu chứng lâm sàng chính}

Bảng 2. Triêuu chứng lâm sàng chính.

\begin{tabular}{|c|c|c|c|c|}
\hline Triệu chứng & Khôii u & Loét & Đau & Abccess \\
\hline K tế bào vảy & 6 & 5 & & \\
\hline K tế bào đáy & 5 & 5 & & \\
\hline Sarcom & & & 2 & \\
\hline K màng não & & & 1 & \\
\hline K tuyến bã & & & & 1 \\
\hline Tống & $\mathbf{1 1 / 2 5}$ & $\mathbf{1 0 / 2 5}$ & $\mathbf{0 3 / 2 5}$ & $\mathbf{0 1 / 2 5}$ \\
\hline
\end{tabular}

Nhân xét: Chủ yếu bênh nhân đến khám và điều trị bởi biểu hiện có khối bất thường và các u sùi loét vùng da đầu.

3.4. Vị trí - kích thước tổn khuyết sau cắt tổn thương

Bảng 3. Vị trí - kích thước tổn khuyết.

\begin{tabular}{|c|c|c|c|}
\hline Vị trí/Kích thước & $<\mathbf{5} \mathbf{c m}^{2}$ & $\mathbf{5 - 2 0} \mathbf{c m}^{2}$ & $\mathbf{> 2 0} \mathbf{c m}^{\mathbf{2}}$ \\
\hline Trán & 2 & 1 & 1 \\
\hline Đỉnh & & 2 & 3 \\
\hline Đỉnh - chấm & & & 5 \\
\hline Chấm & 1 & 1 & 1 \\
\hline Thái dương & 4 & 1 & 2 \\
\hline Thái dương-đỉnh & & & 1 \\
\hline Tổng & $\mathbf{7 / 2 5}$ & $\mathbf{5 / 2 5}$ & $\mathbf{1 3 / 2 5}$ \\
$\mathbf{( 2 8 \% )}$ & $\mathbf{( 2 0 \% )}$ & $\mathbf{( 5 2 \% )}$ \\
\hline
\end{tabular}

Nhận xét: Vùng da đâu có tốn thương hay gặp là vùng đỉnh, đỉnh - chẩm và thái dương với tỳ lệ tổn khuyết lớn $>20 \mathrm{~cm}^{2}$ chiếm $52 \%$.

3.5. Thành phân xâm nhiễm của tổn thương Bảng 4. Thành phần xâm nhiễm của tổn thương Loại

\begin{tabular}{|c|c|c|c|c|}
$\begin{array}{c}\text { K/Thà̀nh } \\
\text { phân tổn } \\
\text { thương }\end{array}$ & Da & Cốt mạd & Xương & $\begin{array}{c}\text { Màng } \\
\text { não }\end{array}$ \\
\hline K tế bào vảy & 11 & 3 & 3 & \\
\hline K tế bào đáy & 10 & 1 & 1 & \\
\hline Sarcom & 2 & 2 & & \\
\hline K màng não & 1 & 1 & 1 & 1 \\
\hline K tuyển bã & 1 & & & \\
\hline Tống & $\mathbf{2 5 / 2 5}$ & $\mathbf{0 7 / 2 5}$ & $\mathbf{0 5 / 2 5}$ & $\mathbf{1}$ \\
\hline
\end{tabular}

Nhận xét: Nguyên nhân chính thường do $\mathrm{K}$ tế bào vảy và tế bào đáy; với chiều sâu tổn thương thường xâm nhiễm hết toàn bộ các lớp sinh lý của da là chủ yếu.

3.6. Loại phẫu thuật

Bảng 5. Các phương pháp đóng tổn khuyêt.

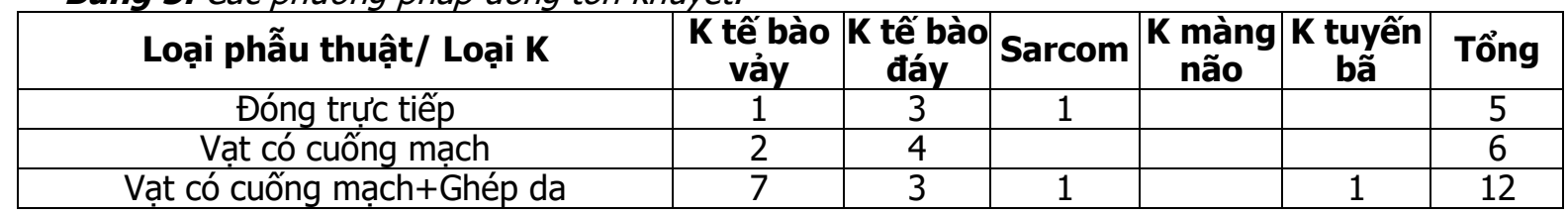




\begin{tabular}{|c|c|c|c|c|c|c|}
\hline Vạt có cuống mạch+Lưới titan+Ghép da & & 1 & & 1 & \\
\hline Vạt tự do & & & & & & 0 \\
\hline
\end{tabular}

Nhâan xét: Phương pháp phẫu thuật sử dụng vạt có cuống mạch hoặc vạt có cuống mạch kết hợp ghép da là phương pháp được sử dụng chính.

3.7. Kết quả phẫu thuât
Bảng 6. Kết quả sau mô.
\begin{tabular}{|c|c|c|}
\hline Kết quả & Gần & Xa \\
\hline Tốt & $17 / 25(68 \%)$ & $20 / 25(80 \%)$ \\
\hline Khá & $08 / 25(32 \%)$ & $05 / 25(20 \%)$ \\
\hline Kém & $0 / 25(0 \%)$ & $0 / 25(0 \%)$ \\
\hline
\end{tabular}

Nhân xét: Tất cả các ca phầu thuật đều có kết quả tốt và khá, trong đó có 03 trường hợp tiến triển tốt lên khi đánh giá kết quả xa.

\section{BÀN LUẦN}

4.1. Về tuổi, giới, nguyên nhân, đặc điểm tổn thương. 25 bệnh nhân được chọn có độ tuổi trung bình là 66,33 (+/- 17,85; trẻ tuổi nhất là 31 tuổi, lớn tuổi nhất là 72). Trong một số nghiên cứu trước đây đã chỉ ra tỷ lệ $\mathrm{K}$ da đầu thường gặp hơn nữ và trong nghiên cứu này tỷ lệ mắc giửa nam và nữ cũng có kết quả tương tự (Nam: 15/25 - 60\%; Nữ: 10/25 - 40\%).

Trong nhóm đối tượng này, nguyên nhân chính dẩn đến tổn khuyết da đâu là do hai thể $\mathrm{K}$ tế bào chính (tế bào đáy và tế bào vảy) trong các ung thư da không phải melanom gây nên (21/25 $84 \%)$. Kết quả này tương đồng với các kết quả đã được báo cáo trong nghiên cứu trước đây.

4.2. Về triệu chứng lâm sàng chính khiến bệnh nhân đỉ điêuu trị: Triệu chứng lâm sàng khiến bệnh nhân phải nhập viên điều trị chính là do các khối u sùi loét (21/25 - 84\%) do $K$ tế bào vảy hoặc $K$ tế bào đáy da đầu gây nên. Triệu chứng đau chỉ xuất hiện trên bệnh nhân sracom và $\mathrm{K}$ màng não $(03 / 25-12 \%)$ và do khối abcess do K tuyến bã chỉ có một bệnh nhân (01/25 - 4\%).

4.3. Về vị trí và kích thước tổn thươngtổn khuyết: Archontaki $M$. và cộng sự đã có báo cáo về vị trí thường xuất hiện của nhóm $\mathrm{K}$ tế bào đáy kích thước lớn da đầu tại vùng chẩm phía sau trên 51 đối tượng [4]. Trên nhóm 25 đối tượng của nghiên cứu, diện tổn khuyết lớn $\left(>20 \mathrm{~cm}^{2}\right)$ chiếm đa số $(13 / 25$ - 52\%) với kích thước lớn nhất là $380 \mathrm{~cm}^{2}$. Vị trí các tổn thương tâp trung chủ yếu tại vùng đỉnh và chẩm (13/25 - 52\%) và tỷ lệ giữa nam và nữ không có sự khác biệt lớn (Nam: 07/25 - 28\%; Nữ: 06/25 - 24\%).

4.4. Về thành phân tổn thương. Trong nhóm nghiên cứu có $07 / 25$ bệnh nhân $(28 \%)$ với diện tổn thương rộng và thâm nhiễm sâu (cốt mạc, xương, màng não) với bốn bệnh nhân được chẩn đoán mô bệnh học với $K$ tế bào vảy và một chẩn đoán $\mathrm{K}$ tế bào đáy xâm nhiễm đến cốt mạc.
Nguyên nhân dẫn đến tình trạng thâm nhiễm của bốn bênh nhân này, mà không phải do các thể hay gặp ( $K$ tế bào đáy, $K$ tuyến,...) như đã được nhắc đến ở nghiên cứu trước [4], đều do đến điều trị muộn hoặc bị bỏ sót tổn thương khi điều trị ở tuyến dưới tương tự như nguyên nhân được nêu đến trong nghiên cứu của Uwe Wollina (2019).

4.5. Về phương pháp phẫu thuật . Chỉ định phương pháp phẩu thuật (PPPT) dựa trên diện tích tổn khuyết da đầu sau cắt bỏ khối $\mathrm{K}$ :

- Tổn khuyết nhỏ $\left(<5 \mathrm{~cm}^{2}\right)$ : đóng trực tiếp vết mổ.

- Tổn khuyết trung bình $\left(5-20 \mathrm{~cm}^{2}\right)$ : sử dụng vạt tại chỗ ngẫu nhiên hoặc vạt đảo, vạt có cuống nếu cần và đóng trực tiếp nơii cho vạt

- Tổn khuyết lớn $\left(>20 \mathrm{~cm}^{2}\right)$ : sử dụng vạt cuống động mạch thái dương nông hoặc động mạch chẩm kết hợp ghép da xẻ đôi che phủ phần cho vạt.

Trong nghiên cứu này, đối với các tổn khuyết nhỏ và trung bình, chỉ định PPPT được dùng tương tự như trong các nghiên cứu trước và đối với nhóm tổn khuyết lớn, một số tác giả đưa ra chỉ định PPPT như: khoan bản sọ biểu mô chờ ghép da, ghép da nhân tạo (Integra) hoăc sử dụng vạt tự do vi phẫu thuật với các tổn khuyết lớn $[5,6]$. Điểm khác biệt trong nghiên cứu này đó là chúng tôi áp dụng PPPT tạo hình sử dụng vạt cuống động mạch thái dương nông hoặc động mạch chẩm kết hợp ghép da xẻ đôi che phủ phần cho vạt.

4.5. Về kết quả phẫu thuật. Các tác giả Nguyễn Bắc Hùng (2017) và Trần Thiết Sơn (2007) đã tổng kết và đưa ra các tiêu chí lượng giá nhằm đánh giá kết quả tạo hình dựa trên sức sống của vat, diện tích che phủ, tình trạng da đầu vùng tổn khuyết và tình trang mọc tóc của vùng da đầu mang tóc $[1,3]$, chúng tôi cũng dựa trên các tiêu chí đó để đánh giá như sau: Trong kết quả gần, $17 / 25$ bệnh nhân $(68 \%)$ có kêt quả tốt. Trong đó, $07 / 25$ bệnh nhân (28\%) là các tổn khuyết nhỏ được đóng vết mổ trực tiếp và $05 / 25$ bệnh nhân $(20 \%)$ là các tổn khuyết trung bình sứ dụng PPPT tạo hình bằng vạt ngẫu nhiên và có $05 / 25$ bệnh nhân $(20 \%)$ của nhóm có tổn khuyết lớn sử dụng vạt cuống động mạch thái dương nông hoặc động mạch chẩm kết hợp ghép da xẻ đôi.

Sau khi đánh giá kết quả xa, số lượng kết quả tốt tăng thêm ba bệnh nhân từ nhóm sử dụng vạt 
cuống mạch - ghép da (20/25-80\%) và không có kết quả xấu nào trong cả hai thời điểm đánh giá. Kết quả này cho thấy, chỉ định PPPT đóng trực tiếp và vat ngẫu nhiên với các tổn khuyết nhỏ $(<5$ $\left.\mathrm{cm}^{2}\right)$ - trung bình $\left(5-20 \mathrm{~cm}^{2}\right)$ cho kết quả tốt và tương tự với kết quả của các tác giả Cherubino. $M(2013)$, Cleyton.D. Souza (2012) [5,6].

Bên cạnh đó, kết quả trên gợi ý rằng, với các tổn khuyết lớn $\left(>20 \mathrm{~cm}^{2}\right)$, việc sử PPPT kết hợp vạt cuống động mạch thái dương nông hoặc động mạch chẩm và ghép da mang lại kết quả sau phẫu thuật rất khả quan với tỷ lẹ̣ vạt sống cao và kết quả xa tốt lên, cũng như đảm bảo các yêu cầu thẩm mỹ về vùng da có tóc. Bên cạnh đó, kết hợp kết quả này với độ tuổi trung bình tương đối lớn của nhóm đối tượng trong nghiên cứu $(66,33$; +/- 17,85; trẻ tuổi nhất là 31 tuổi, lớn tuổi nhất là 72) đã gợi ý rằng việc áp dụng PPPT kết hợp vạt cuống động mạch thái dương nông hoặc động mạch chẩm và ghép da sẽ phù hợp và giúp đạt kết quả phẫu thuật tốt nhất với tình trạng lâm sàng của nhóm bệnh nhân cao tuổi.

\section{KẾT LUÂNN}

Vùng da đầu có tổn thương hay gặp là vùng đỉnh, đỉnh - chẩm và thái dương, tỷ lệ tổn khuyết vừa và lớn chiếm $72 \%$, có $28 \%$ thâm nhiếm sâu (cốt mạc, xương, màng não).

Kết quả phẫu thuật cho thấynhóm bệnh nhân chỉ định PPPT đóng trực tiếp với các tổn khuyết nhỏ $\left(<5 \mathrm{~cm}^{2}\right)$ và sử dụng vạt da cân ngẫu nhiên với các tổn khuyết trung bình $\left(5-20 \mathrm{~cm}^{2}\right)$ là hoàn toàn phù hợp, đồng thời chỉ định PPPT kết hợp vạt cuống động mạch thái dương nông hoặc động mạch chẩm kết hợp ghép da xẻ đôi che phủ phần cho vạt để che phủ các tổn khuyết lớn $\left(>20 \mathrm{~cm}^{2}\right.$ ) là phương án hữu dụng, an toàn, cho kêt quả tốt nhất là đối với nhóm bênh nhân lớn tuổi có nhiều yếu tố bệnh lý nền, thể trạng sức khoẻ không đảm bảo cho các phương pháp khác như giãn da, vi phẫu.

\section{TÀI LIÊU THAM KHẢO}

1. Nguyễn Bắc Hùng (2017), Bài giảng phâu thuật tạo hình thẩm mỹ.

2. Nguyễn Huy Phan (1999), Lịch sử phát triển kỹ thuât vi phấu thân kinh trên thế giới và ở Viêt Nam.

3. Trân Thiết Sơn (2007), Nhận xét các kết quả tạo hình khuyết lớn da đầu.

4. Archontaki M., et al (2009). Giant Basal Cell Carcinoma: Clinicopathological Analysis of 51 Cases and Review of the Literature. Anticancer Research 29: 2655-2664.

5. Cherubino M., et al. (2013). A New Algorithm for The Surgical Management of Defects of the Scalp. ISRN Plast Surg, 2013, 1-5.

6. Cleyton .D. Souza (2012). Reconstruction of large scalp and forehead defects following tumor resection: personal strategy and experience - analysis of 25 cases. Rev Bras Cir Plást. 2012;27(2):227-37.

7. Keck M, et al (2012). Primary cutaneous adenoid carcinoma of the scalp. GMS Interdiscip Plast Reconstr Surg DGPW. 2012;1:Doc04

8. Onishi K., et al. (2005). Repair of scalp defect using a superficial temporal fascia pedicle $\mathrm{VY}$ advancement scalp flap. Br J Plast Surg, 58 (5), 676-680.

\title{
KHẢO SÁT MỨC Độ HOÀN THIỀN CỦA HÊ THỐNG TỔ CHỨC Y TẾ TRONG QUẢN LÝ MỸ் PHẨM TẠI VIỆT NAM
}

\author{
Hoàng Thy Nhạc Vũ*, Trần Thị Ngọc Vân*, Lê Thị Kiều Oanh*
}

\section{TÓM TẮT}

Mục tiêu: Nghiên cứu nhằm khảo sát mức độ hoàn thiện của hệ thống tổ chức y tế trong quản lý mỹ் phẩm tại Việt Nam. Đối tượng và phương pháp: Nghiên cứu được thực hiện thông qua việc tổng hợp và phân tích nội dung các quy định về quản lý mỹ phâm tại Việt Nam, do cấp trung ương ban hành, có pham vi áp dung toàn quốc, và còn hiệu lực tính đến ngày 01/06/2021. Kết quả: Thông qua khung pháp lý hiện hành về quản lý mỹ phẩm tai Việt Nam, với 36 văn bản liên quan đã được ban hành và còn hiệu lực

*Đại hoc Y Dược TP Hồ Chí Minh

Tác giả liên lạc: Hoàng Thy Nhạc Vũ, Email: hoangthynhacvu@ump.edu.vn Ngày nhận bài: 14/5/2021

Ngày phản biên khoa học: 10/6/2021

Ngày duyệt bài: 9/7/2021
(2 Điều ước quốc tế, 5 văn bản Luât, 10 Nghi đinh, 2 văn bản hợp nhất, 10 Thông tư, và 7 Quyết định), có thể thấy cơ quan y tế đã thực hiện vai trò quản lý trong năm lĩnh vực chính, với 12 văn bản vê xuất khẩu, nhập khẩu mỹ phẩm; 8 văn bản về kiểm nghiệm, kiểm tra đảm bảo chất lượng mỹ phẩm; 7 văn bản về công bố sản phẩm mỹ phẩm; 6 văn bản về quảng cáo mỹ phẩm; và 6 văn bản về sản xuất mỹ phẩm. Văn bản hợp nhất số 07/VBHN-BYT năm 2021 và Quyết định số 7866/QĐ-BYT năm 2018 là những văn bản quan trọng vì liên quan đến nhiều lĩnh vực trong quản lý mỹ phẩm. Kết luân: Thông tin thu được đã cung cấp một bức tranh toàn cảnh về vai trò của cơ quan y tế và mức độ hoàn thiện của hệ thống y tế trong quản lý mỹ phẩm tại Việt Nam trong việc thực hiện các giải pháp của chiển lược quốc gia về bảo vệ, chăm sóc và nâng cao sức khỏe nhân dân.

Tư khóa: Chiến lước quốc gia, hệ thống tổ chức y tễ, quản lý mỹ phẩm, khung pháp lý, Việt Nam. 